\title{
Crystalloid Coload Reduced the Incidence of Hypotension in Spinal Anesthesia for Cesarean Delivery, When Compared to Crystalloid Preload: A Meta-Analysis
}

\author{
Hai-Fang Ni, Hua-yue Liu, Juan Zhang, Ke Peng, and Fu-Hai Ji \\ Department of Anesthesiology, First Affiliated Hospital of Soochow University, No. 188 Shizi Street, Suzhou, Jiangsu 215006, China \\ Correspondence should be addressed to Ke Peng; pengke0422@163.com and Fu-Hai Ji; jifuhaisuda@163.com
}

Received 2 August 2017; Revised 7 November 2017; Accepted 16 November 2017; Published 17 December 2017

Academic Editor: Jose Guilherme Cecatti

Copyright (C) 2017 Hai-Fang Ni et al. This is an open access article distributed under the Creative Commons Attribution License, which permits unrestricted use, distribution, and reproduction in any medium, provided the original work is properly cited.

\begin{abstract}
Objective. To determine whether crystalloid infusion just after intrathecal injection (coload) would be better than infusion before anesthesia (preload) for hypotension prophylaxis in spinal anesthesia for cesarean delivery. Methods. We searched PubMed, EMBASE, Cochrane Central Register of Controlled Trials, and other databases for randomized controlled trials comparing coload of crystalloid with preload in parturients receiving spinal anesthesia for cesarean delivery. Primary outcome was intraoperative incidence of hypotension. Other outcomes were intraoperative need for vasopressors, hemodynamic variables, neonatal outcomes (umbilical artery $\mathrm{pH}$ and Apgar scores), and the incidence of maternal nausea and vomiting. We used RevMan 5.2 and STATA 12.0 for the data analyses. Results. Ten studies with 824 cases were included. The incidence of hypotension was significantly higher in the preload group compared with the coload group $(57.8 \%$ versus $47.1 \%$, odds ratio $[\mathrm{OR}]=1.62,95 \%$ confidence interval $[\mathrm{CI}]=$ $1.11-2.37$, and $P=0.01)$. More patients needed intraoperative vasopressors $(\mathrm{OR}=1.71,95 \% \mathrm{CI}=1.07-2.04$, and $P=0.02)$ when receiving crystalloid preload. In addition, the incidence of nausea and vomiting was higher in the preload group $(\mathrm{OR}=3.40,95 \%$ $\mathrm{CI}=1.88-6.16$, and $P<0.0001)$. There were no differences in neonatal outcomes between the groups. Conclusions. For parturients receiving crystalloid loading in spinal anesthesia for cesarean delivery, coload strategy is superior to preload for the prevention of maternal hypotension.
\end{abstract}

\section{Introduction}

Cesarean section is one of the most commonly performed surgical procedures worldwide, and $80-90 \%$ of them are performed under spinal anesthesia [1]. During the procedures, maternal hypotension is a major complication with the incidence up to $60-70 \%[2,3]$. The risk factors for hypotension are preoperative hypertension, age, type of anesthesia, and the infant weight [4]. Besides, pregnant women are characterized by increased sympathetic versus parasympathetic activities [5], contributing to the sensitivity to spinal block and vasodilatation [6].

Prolonged hypotension leads to organ ischemia, uteroplacental hypoperfusion loss of consciousness, and cardiovascular collapse [7]. Fluid administration is a daily practice to prevent and treat maternal hypotension. However, the optimal fluid and timing of infusion are yet to be determined. Some studies showed that colloids may be more effective than crystalloids for preventing hypotension $[8,9]$. As for colloids, the preload group had lower incidence of hypotension than the coload group [10], but the administration of additional $0.5 \mathrm{~L}$ offered no added benefits [6]. However, there are several disadvantages associated with colloids, such as cost, allergic reactions, and their effects on coagulation. As a result, crystalloids are still preferred by many anesthesiologists.

The timing of crystalloid infusion is of great importance because it distributes rapidly into the extracellular space and the volume expanding effect is maximal at the early stage. Traditionally, preload of fluids is used to prevent hypotension in spinal anesthesia, but the efficacy has been questioned. Studies found that fluid coload at the time of actual block during spinal anesthesia was more effective [11, 12]. A previous meta-analysis suggested that the timing of fluid loading did not influence the incidence of hypotension [13], but it combined crystalloid and colloid with only a limited data for crystalloid. In this meta-analysis, we therefore compared 
coload of crystalloid with preload to determine the optimal timing of infusion for preventing hypotension in spinal anesthesia for cesarean section.

\section{Material and Methods}

2.1. Search Strategy. We adhered to the guidelines of the Cochrane Handbook for Systematic Reviews of Interventions throughout this meta-analysis. We searched all relevant trials in the following databases: PubMed, EMBASE, Cochrane Central Register of Controlled Trials, Research Gate, and LILACS, without language or publication date restrictions. The search strategy for PubMed and EMBASE is shown in Supplementary Table 1. Additional studies were retrieved by review of the reference lists from relevant articles.

\subsection{Inclusion Criteria}

(i) Randomized controlled trial (RCT)

(ii) Healthy parturients scheduled for cesarean delivery under spinal anesthesia

(iii) Use of crystalloids for preload compared to coload

(iv) Outcome measures including intraoperative hypotension, need for vasopressors, intraoperative hemodynamic variables such as heart rate (HR), systolic blood pressure (SBP), and mean arterial pressure (MAP), neonatal outcomes ( $\mathrm{pH}$ of umbilical artery and Apgar scores), and the incidence of maternal nausea and vomiting

2.3. Primary and Secondary Outcomes. The primary outcome was the incidence of hypotension. Secondary outcome measures were need for vasopressors, intraoperative HR, SBP, and MAP, umbilical artery $\mathrm{pH}$, Apgar scores, and nausea and vomiting.

2.4. Data Extraction. Data were extracted independently by two investigators and any discrepancy was resolved by group consensus. The following data were extracted: author, publication year, sample size, study design (randomization, blind, allocation concealment, and follow-up), anesthesia, interventions, and outcome measures of interest. The authors of the included studies were contacted for additional information if data was not available from the text.

2.5. Study Quality Assessment. The risk of bias was evaluated by two authors independently with the Cochrane Collaboration tool [22]. For each domain, the risk of bias was judged as "high," "low," or "unclear." A trial was considered to have a high risk of bias when one or more domains were at high risk and a low risk of bias when all domains were at low risk. Otherwise, it was judged to have an unclear risk of bias. Any discrepancy over bias assessment was resolved by group discussion.

2.6. Statistical Methods. We performed analyses using the RevMan 5.2 (the Cochrane Collaboration, Copenhagen, Denmark) and STATA 12.0 (Stata Corp, College Station, TX).

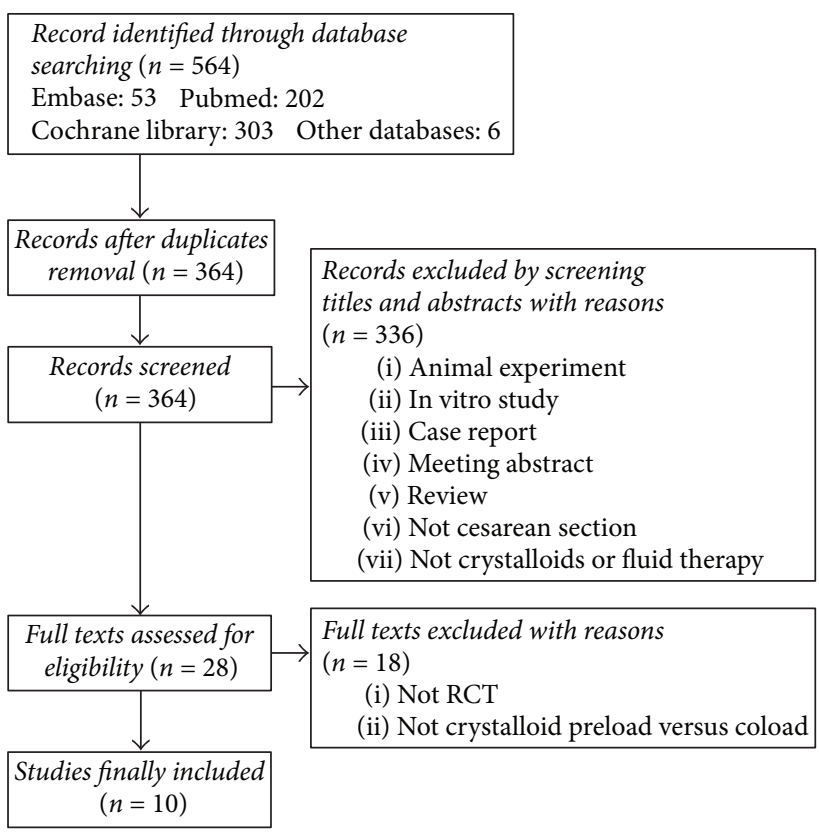

FIGURE 1: Flow diagram of study selection.

For continuous data, mean difference (MD) with 95\% confidence intervals (CIs) was used; for dichotomous outcomes, odds ratio (OR) with $95 \%$ CIs was used. We evaluated the statistical heterogeneity of the results with the chi-squared test and the $I^{2}$ statistic, with $I^{2}>50 \%$ indicating significant heterogeneity [23]. A random-effects model was used in this meta-analysis [24]. Publication bias was evaluated using a funnel plot. Sensitivity analysis was performed to assess the effect of a single comparison on the overall estimates. A $P$ value of $<0.05$ was considered to be statistically significant.

When range or interquartile range was reported, we estimated the standard deviation as range/4 (range $=$ maximum value-minimum value) or interquartile range/1.35 (interquartile range $=\mathrm{Q} 3-\mathrm{Q} 1$, with $\mathrm{Q} 1$ and $\mathrm{Q} 3$ representing the first and third quartiles, resp.) [25]. When standard error or CI was reported, standard deviation was calculated with the calculator of RevMan. To increase the robustness of results, data were pooled when at least 3 trials were included for an outcome.

\section{Results}

3.1. Study Selection and Characteristics. The flow diagram is shown in Figure 1. Ten trials [11, 12, 14-21] with 824 patients were eligible for inclusion into this study. The characteristics are summarized in Table 1 . These studies were published from 2004 to 2017 with population sizes ranging from 50 to 120 . All studies applied spinal anesthesia for cesarean section. Nine studies enrolled healthy parturients scheduled for elective surgery and one for emergency delivery.

In these studies, hypotension was defined as a $20 \%$ decrease from baseline in MAP or SBP, or SBP $<90 \mathrm{mmHg}$. Seven studies $[11,12,15-18,21]$ used ephedrine to treat intraoperative hypotension, two studies $[14,19]$ used ephedrine or phenylephrine, and mephentermine was selected in one 


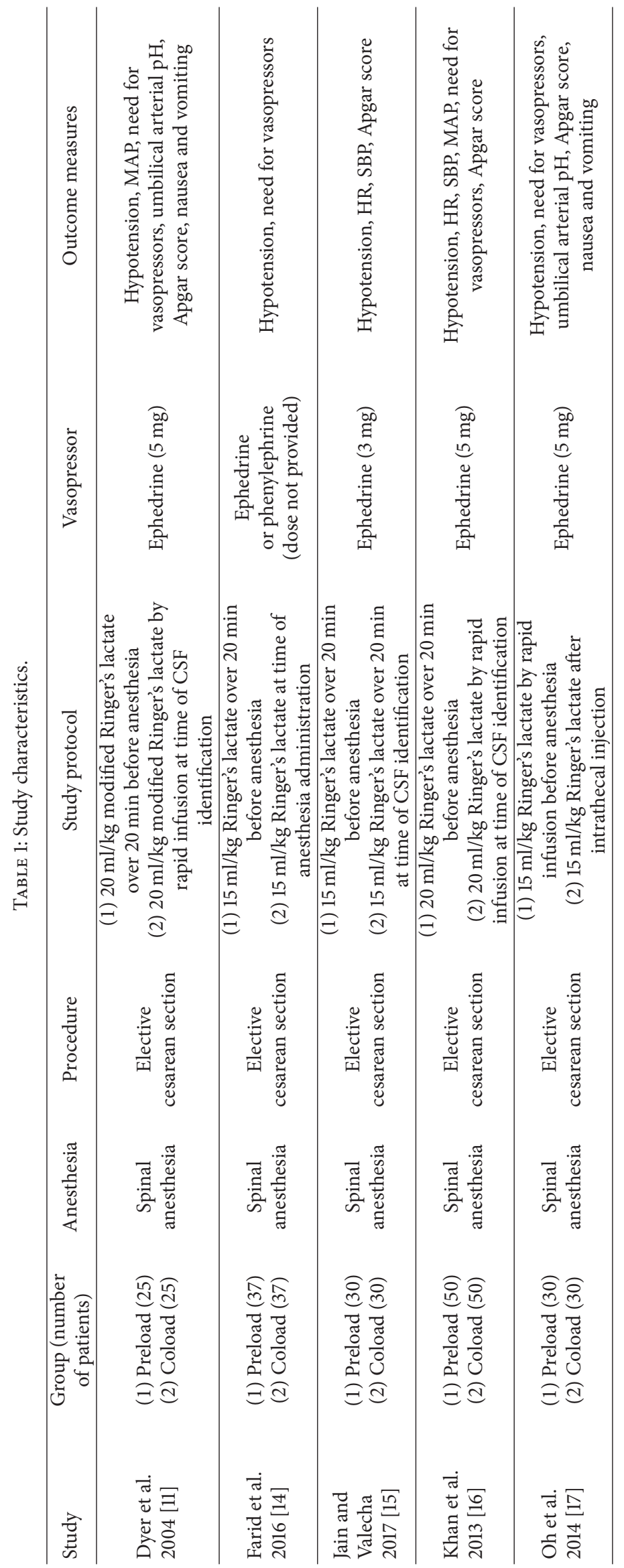




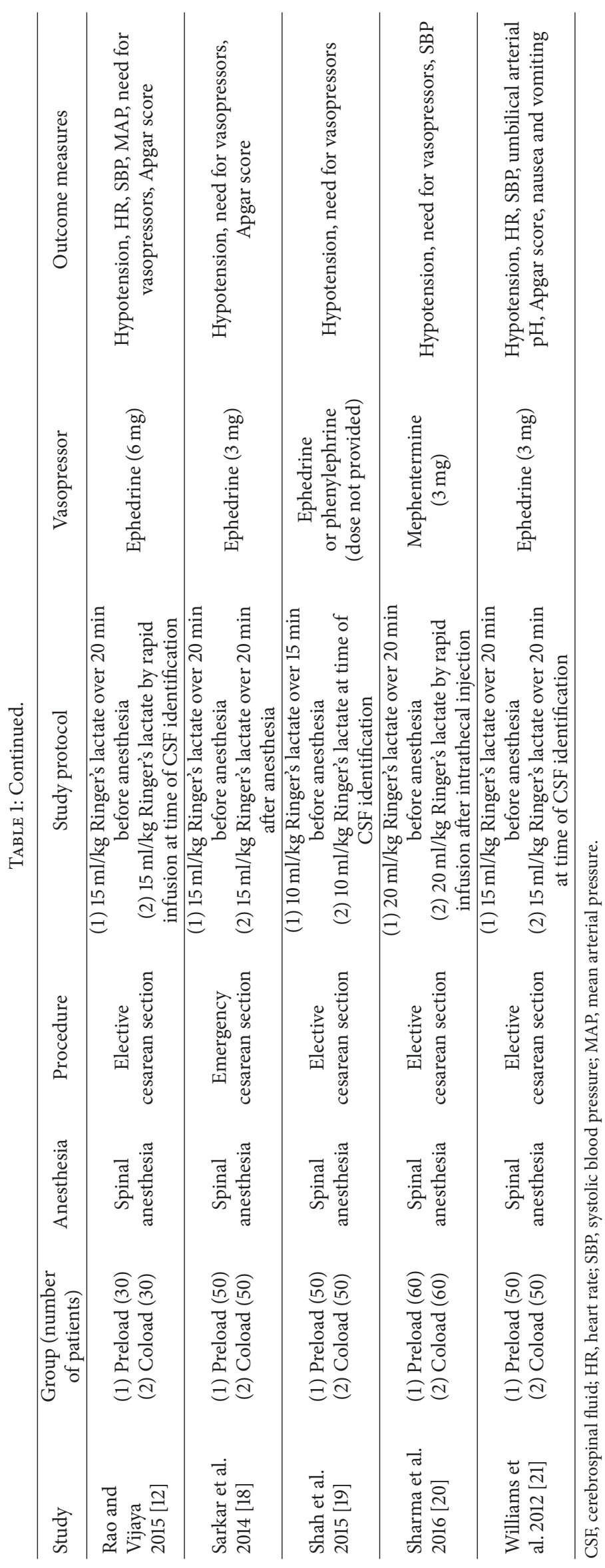




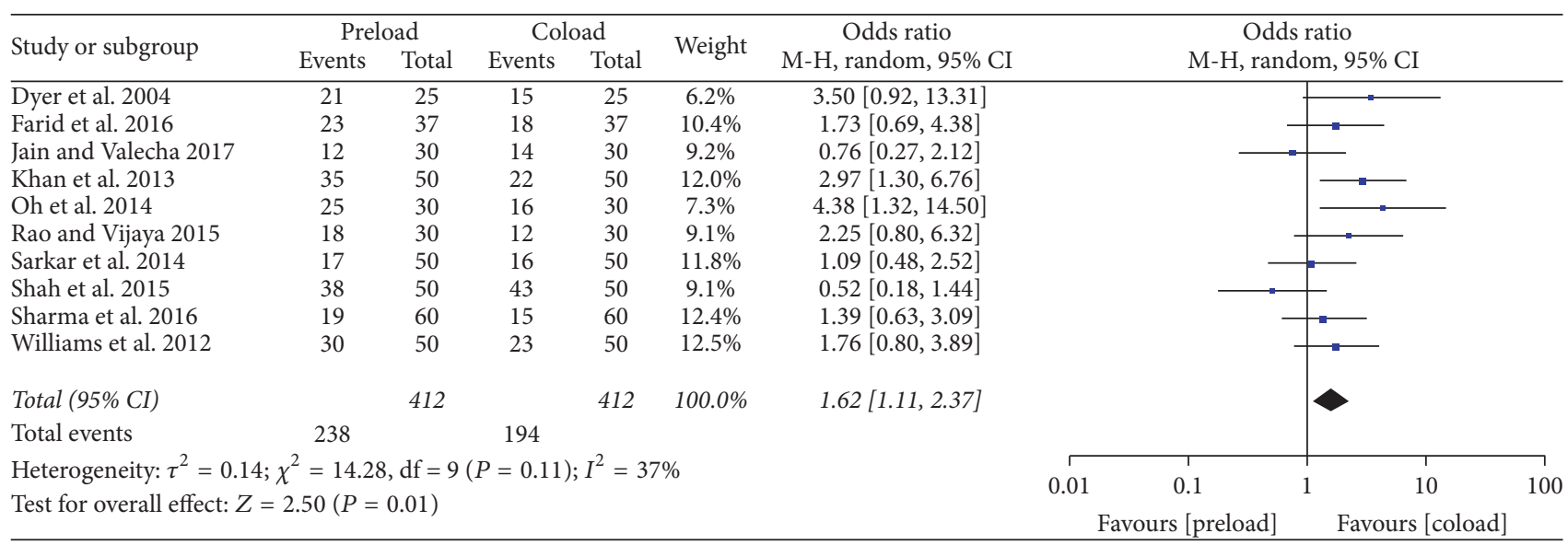

(a)

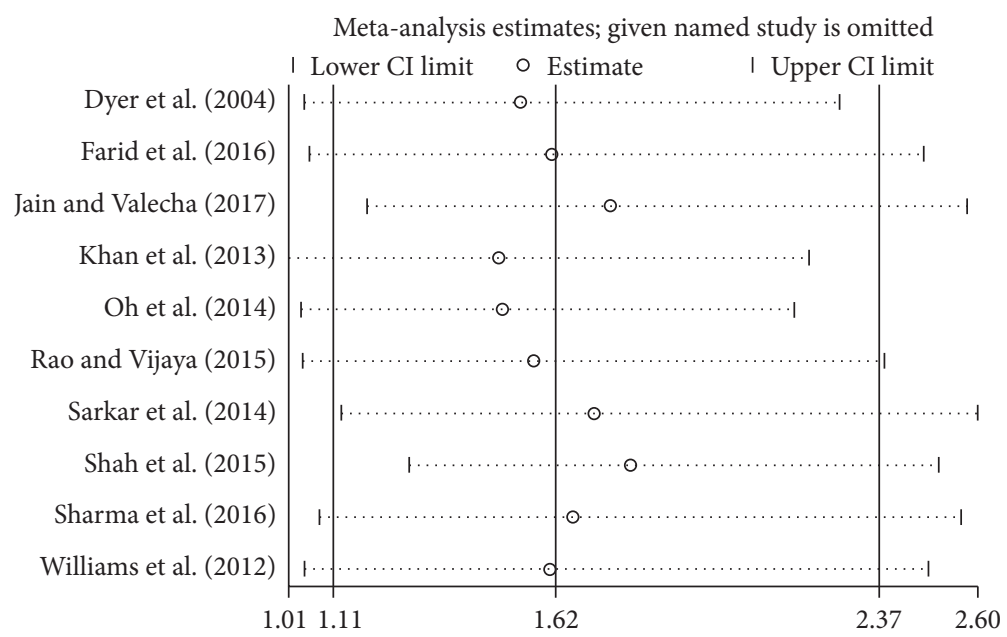

(b)

FIGURE 2: Intraoperative hypotension: (a) forest plot; (b) sensitivity analysis.

study [20]. Seven studies [11, 12, 14, 16, 17, 19, 20] used vasopressors when patients developed hypotension, while one study [18] combined crystalloid boluses and ephedrine. Nine studies [11, 12, 14-18, 20, 21] recorded the number of patients with hypotension throughout the surgery, and one study [19] recorded hypotension at 3 and $5 \mathrm{~min}$ after anesthesia induction.

3.2. Incidence of Hypotension and Need for Vasopressors. Pooled data from ten studies [11, 12, 14-21] showed that patients in the crystalloid preload group had more hypotensive episodes than those in the coload group $(57.8 \%$ versus $47.1 \%, \mathrm{OR}=1.62,95 \% \mathrm{CI}=1.11-2.37$, and $P=0.01)$ (Figure 2(a)). Sensitivity analysis reflected that these findings were robust (Figure 2(b)), with pooled ORs ranging from 1.49 $(95 \% \mathrm{CI}=1.01-1.29)$ to $1.80(95 \% \mathrm{CI}=2.18-2.60)$. The funnel plot with hypotension as an endpoint appeared symmetrical, suggesting that publication bias might not affect the results (Figure 3).

Eight studies $[11,12,14,16-20]$ compared the needs for vasopressors between the preload and coload groups. The results indicated a significant increase in the need for

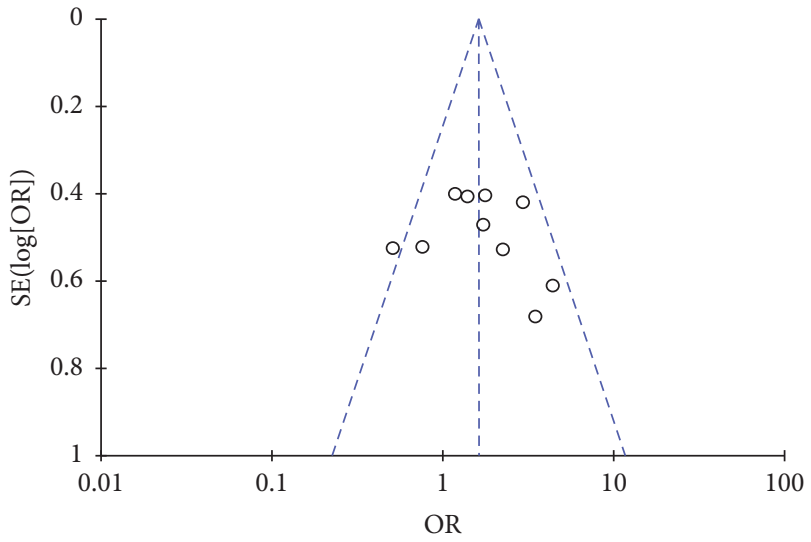

FIGURE 3: Funnel plot with hypotension as an endpoint.

vasopressors when patients received fluid preload $(\mathrm{OR}=$ 1.71, 95\% CI $=1.07-2.04$, and $P=0.02$ ) (Figure 4(a)). Sensitivity analysis reflected that these findings were robust (Figure 4(b)), with pooled ORs ranging from 1.54 (95\% CI = $0.94-1.30)$ to 1.95 (95\% CI $=2.47-3.16$ ). 


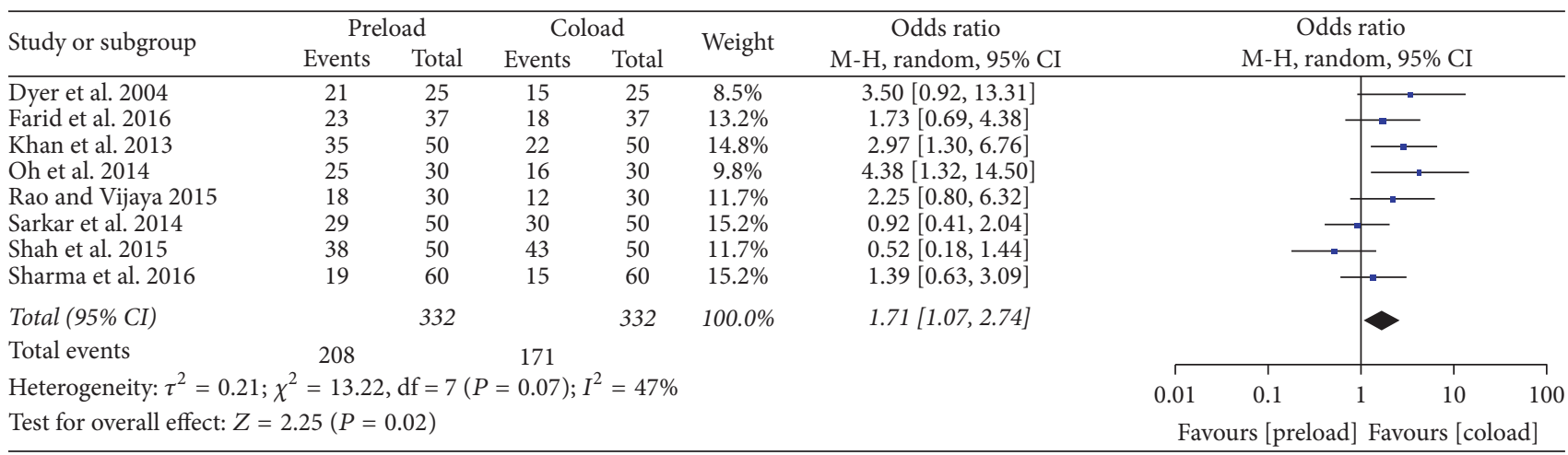

(a)

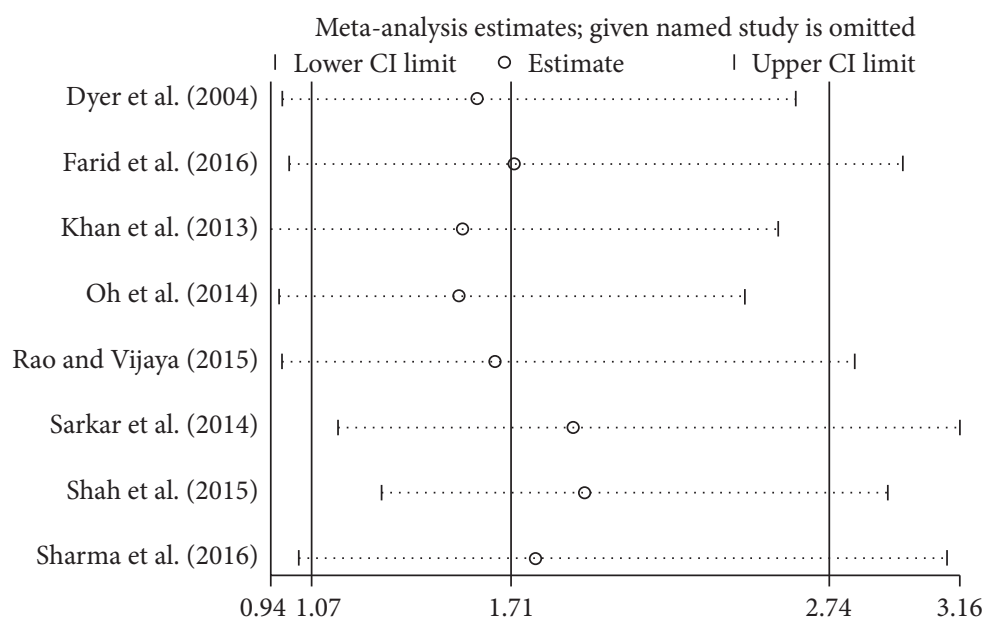

(b)

FIGURE 4: Intraoperative need for vasopressors: (a) forest plot; (b) sensitivity analysis.

3.3. Hemodynamic Variables. Intraoperative $\mathrm{HR}, \mathrm{SBP}$, and MAP are shown in Figure 5. Four studies [12, 15, 16, 21] reporting on HR during $60 \mathrm{~min}$ after spinal anesthesia showed a higher $\mathrm{HR}$ in the preload group ( $\mathrm{MD}=2.18$ beats $/ \mathrm{min}, 95 \%$ $\mathrm{CI}=0.02-4.35$, and $P=0.05)$. Five studies $[12,15,16,20,21]$ on SBP found no significant difference between the groups. Additionally, the preload group had higher MAP during $20 \mathrm{~min}$ after spinal anesthesia $(\mathrm{MD}=3.25 \mathrm{mmHg}, 95 \% \mathrm{CI}=$ 1.63-4.87, and $P<0.0001)[11,12,16]$.

3.4. Other Outcomes. There was no significant difference in umbilical arterial $\mathrm{pH}$ between the two groups (Figure 6(a)). Seven studies [11, 12, 15-18, 21] analyzed Apgar scores, and none of them reported Apgar scores $<7$ at $5 \mathrm{~min}$. Data from 4 studies $[11,15,17,21]$ showed that the incidence of nausea and vomiting was higher in the preload group $(\mathrm{OR}=3.40,95 \% \mathrm{CI}$ $=1.88-6.16$, and $P<0.0001$ ) (Figure 6(b)).

3.5. Risk of Bias Assessment. The risk of bias assessment is presented in Table 2. Overall, all studies were doubleblinded and randomized. Two studies adequately reported the random sequence generation $[15,19]$, and five trials clearly reported the allocation concealment [11, 15, 17, 20, 21].

\section{Discussion}

The results of this meta-analysis suggested that coload infusion of crystalloid reduced the incidence of hypotension compared to preload in parturients receiving spinal anesthesia for cesarean delivery. The superiority of coload was further evidenced by a decreased need for vasopressors and a lower incidence of nausea and vomiting.

Crystalloid preload is at times ineffective for preventing hypotension. A previous study by Rout et al. reported that crystalloid preload led to a significant increase in central venous pressure after spinal anesthesia for cesarean section, but the incidence of hypotension was not reduced [26]. The study by Mercier compared four methods of intravascular fluid loading by combining different types of fluid (crystalloid versus colloid) and the timing of administration (preload versus coload). They found that crystalloid preloading or no fluid administration was less likely effective than crystalloid coload for preventing hypotension [27]. According to Starling's law, the exchange of fluid is determined by the capillary and interstitial fluid hydraulic pressure and oncotic pressure [28]. The capillary hydraulic pressure increases over time during crystalloid infusion, which may lead to increased hydraulic pressure difference and fluid filtration from plasma into 


\begin{tabular}{|c|c|c|c|c|c|c|c|c|c|c|c|}
\hline \multirow{2}{*}{ Study or subgroup } & \multicolumn{3}{|c|}{ Preload } & \multicolumn{3}{|c|}{ Coload } & \multirow{2}{*}{ Weight } & \multirow{2}{*}{$\begin{array}{c}\text { Mean difference } \\
\text { IV, random, } 95 \% \text { CI }\end{array}$} & \multirow{2}{*}{\multicolumn{3}{|c|}{$\begin{array}{c}\text { Mean difference } \\
\text { IV, random, } 95 \% \text { CI }\end{array}$}} \\
\hline & Mean & $\mathrm{SD}$ & Total & Mean & SD & Total & & & & & \\
\hline Jain and Valecha 2017 & 83.41 & 7.69 & 30 & 84.41 & 7.28 & 30 & $18.6 \%$ & $-1.00[-4.79,2.79]$ & \multicolumn{3}{|c|}{-1} \\
\hline Khan et al. 2013 & 92 & 4.27 & 50 & 88.59 & 4.64 & 50 & $33.7 \%$ & $3.41[1.66,5.16]$ & \multicolumn{3}{|c|}{-} \\
\hline Rao and Vijaya 2015 & 91.78 & 4.25 & 30 & 87.67 & 4.47 & 30 & $29.8 \%$ & $4.11[1.90,6.32]$ & \multicolumn{3}{|c|}{$\rightarrow-$} \\
\hline Williams et al. 2012 & 79 & 10.49 & 50 & 79.01 & 9.34 & 50 & $18.0 \%$ & $-0.01[-3.90,3.88]$ & \multicolumn{3}{|c|}{-} \\
\hline Total (95\% CI) & & & 160 & & & 160 & $100.0 \%$ & $2.18[0.02,4.35]$ & \multicolumn{3}{|c|}{ 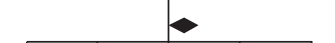 } \\
\hline \multicolumn{9}{|c|}{ Heterogeneity: $\tau^{2}=2.83 ; \chi^{2}=7.68, \mathrm{df}=3(P=0.05) ; I^{2}=61 \%$} & -20 & -10 & 10 \\
\hline \multicolumn{9}{|c|}{ Test for overall effect: $Z=1.98(P=0.05)$} & \multicolumn{3}{|c|}{ Favours [preload] Favours [coload] } \\
\hline
\end{tabular}

(a)

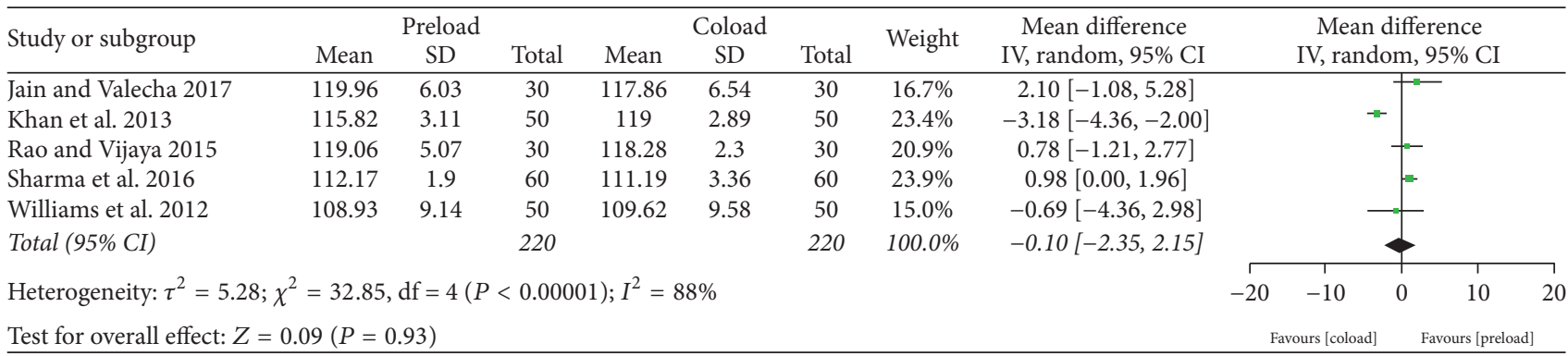

(b)

\begin{tabular}{|c|c|c|c|c|c|c|c|c|c|c|c|c|c|}
\hline \multirow{2}{*}{$\frac{\text { Study or subgroup }}{\text { Dyer et al. } 2004}$} & \multicolumn{3}{|c|}{ Preload } & \multicolumn{3}{|c|}{ Coload } & Weight & $\begin{array}{c}\text { Mean difference } \\
\text { IV, random, } 95 \% \text { CI }\end{array}$ & \multicolumn{5}{|c|}{$\begin{array}{c}\text { Mean difference } \\
\text { IV, random, } 95 \% \text { CI }\end{array}$} \\
\hline & 78.57 & 2.98 & 25 & 74.68 & 3.58 & 25 & $31.4 \%$ & $3.89[2.06,5.72]$ & & & & & \\
\hline Khan et al. 2013 & 82.11 & 2.85 & 50 & 78 & 2.92 & 50 & $41.5 \%$ & $4.11[2.98,5.24]$ & & & & & \\
\hline Rao and Vijaya 2015 & 79.36 & 5.2 & 30 & 78.17 & 3.07 & 30 & $27.1 \%$ & $1.19[-0.97,3.35]$ & & & - & & \\
\hline Total (95\% CI) & & & 105 & & & 105 & $100.0 \%$ & $3.25[1.63,4.87]$ & & & 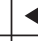 & & \\
\hline \multicolumn{9}{|c|}{ Heterogeneity: $\tau^{2}=1.32 ; \chi^{2}=5.65, \mathrm{df}=2(P=0.06) ; I^{2}=65 \%$} & -20 & -10 & 0 & 10 & 20 \\
\hline \multicolumn{9}{|c|}{ Test for overall effect: $Z=3.92(P<0.0001)$} & & ours [colc & & $\operatorname{urs}[\mathrm{p}$ & \\
\hline
\end{tabular}

(c)

FIGURE 5: Hemodynamic variables: (a) heart rate and (b) systolic blood pressure during 60 min after spinal anesthesia; (c) mean arterial pressure during $20 \mathrm{~min}$ after spinal anesthesia.

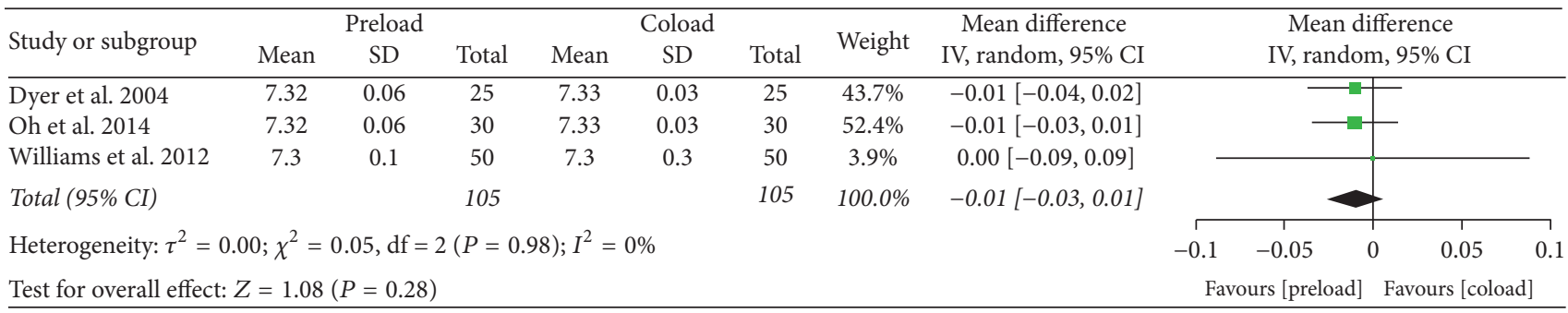

(a)

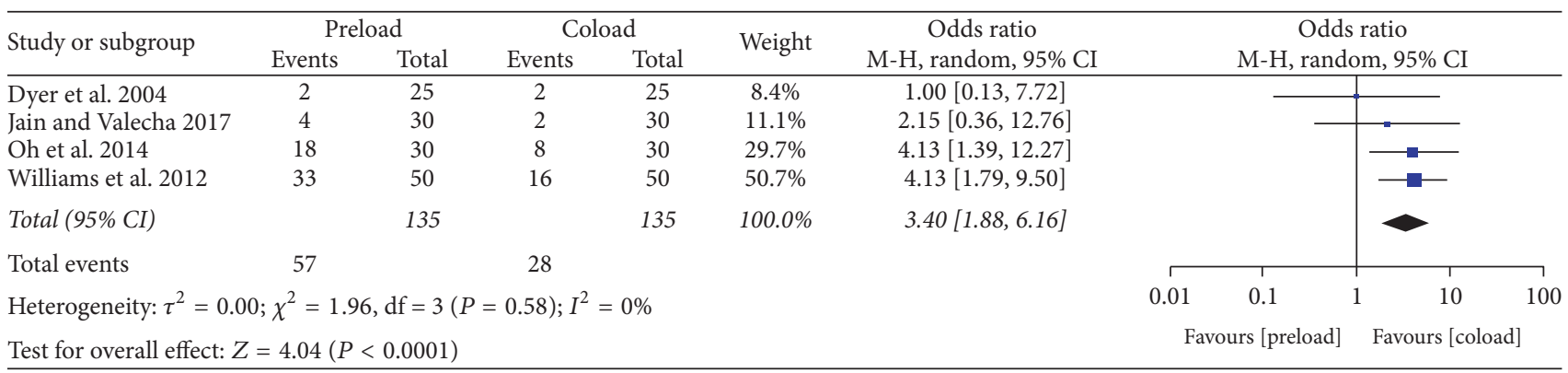

(b)

FIGURE 6: Other outcomes: (a) umbilical arterial pH; (b) nausea and vomiting. 


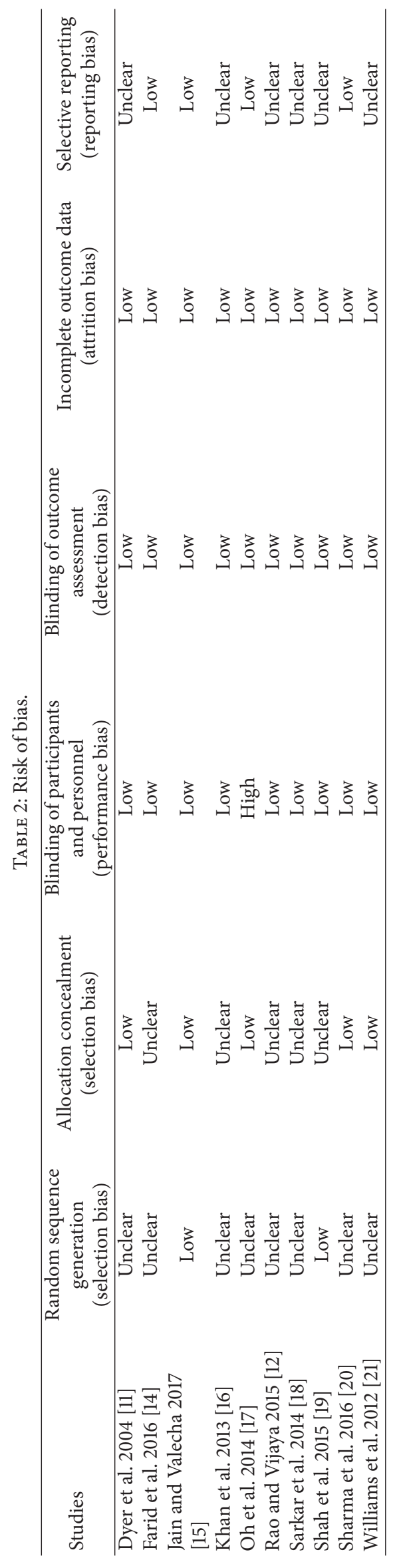


interstitium. An animal experiment on normovolemic sheep found that the maximum intravascular volume expansion was $27 \%$ after infusion, and $15 \%$ after $10 \mathrm{~min}$ and $7 \%$ after $30 \mathrm{~min}$, which indicated a rapid redistribution of crystalloid [29]. Compared with crystalloid preload, coload could help reduce intraoperative hypotension mainly due to the delayed infusion time.

Besides, Pouta et al. suggested that crystalloid preload may induce atrial natriuretic peptide secretion, resulting in peripheral vasodilatation followed by an increased rate of excretion of fluid [30]. Natriuretic peptide type $C$ is a potent vasodilator produced in the endothelium of great vessels [31]. Further fluid loading does not increase the intravascular volume at the time of maximum vasodilation [32]. Atrial natriuretic peptide may even lower blood pressure because of its natriuretic, diuretic, and vasodilatory effects [33]. On the other hand, Ewaldsson and Hahn's study on volume kinetics of Ringer's solution showed that the arterial pressure was better maintained by a fluid bolus just after anesthesia induction compared to preload [34].

In this study, we found that the value of mean HR was lower in the coload group during $60 \mathrm{~min}$ after spinal anesthesia, with a lower value of MAP. This inconsistency may be due to various definitions of hypotension, local anesthetics used, types of vasopressors, and infusion rate of crystalloids. During hemodynamic changes, nausea and vomiting often occur. This meta-analysis also showed that the incidence of nausea and vomiting was lower in the coload group. In the previous meta-analysis by Banerjee et al., there was no difference in the nausea and vomiting between preload and coload regimens [13].

Regarding the neonatal outcomes, umbilical arterial $\mathrm{pH}$ is sensitive to detecting fetal hypoxia, which indicates the hemostasis at birth. In this study, we did not detect any significant difference in umbilical arterial $\mathrm{pH}$ between the groups, and none of the included studies reported Apgar scores $<7$ at $5 \mathrm{~min}$. However, the number of cases included for the outcomes is small. Thus, more studies are needed to ascertain the effects of crystalloid loading on neonatal outcomes.

This study has several limitations. First, all included studies have a relatively small sample size. Second, heterogeneity was detected in the outcomes of intraoperative hemodynamic variables, indicating the differences in the definitions of hypotension and the use of vasopressors; therefore, these results need to be interpreted with caution. However, we performed the sensitivity analyses and found the current results were unlikely affected by one single study. Last, this study failed to detect any beneficial effects of crystalloid infusion regimens on long-term outcomes after cesarean delivery. Further studies with larger sample size investigating the short-term as well as long-term outcomes in this population are required.

\section{Conclusion}

For parturients receiving crystalloid loading in spinal anesthesia for cesarean delivery, coload strategy reduced the incidence of intraoperative maternal hypotension and the need for vasopressors.

\section{Conflicts of Interest}

The authors declare no conflicts of interest.

\section{Authors' Contributions}

Ke Peng and Fu-Hai Ji conceived and designed the study. HaiFang Ni, Ke Peng, Juan Zhang, and Hua-yue Liu performed the study. Ke Peng and Hai-Fang Ni analyzed the data and wrote the paper. All authors read and approved the final manuscript.

\section{Acknowledgments}

This work was supported, in part, by the National Natural Science Foundation of China (Grants 81471835 and 81671880 to Fu-Hai Ji, 81601666 to Juan Zhang, and 81601659 to $\mathrm{Ke}$ Peng) and Jiangsu Province's Youth Medical Talents Program (Grant QNRC2016741 to Ke Peng).

\section{Supplementary Materials}

Supplementary Table 1. Search strategy for PubMed and EMBASE. (Supplementary Materials)

\section{References}

[1] N. J. McDonnell, M. J. Paech, N. A. Muchatuta, S. Hillyard, and E. A. Nathan, "A randomised double-blind trial of phenylephrine and metaraminol infusions for prevention of hypotension during spinal and combined spinal-epidural anaesthesia for elective caesarean section," Anaesthesia, vol. 72, no. 5, pp. 609-617, 2017.

[2] F. J. Mercier, M. Augè, C. Hoffmann, C. Fischer, and A. Le Gouez, "Maternal hypotension during spinal anesthesia for caesarean delivery," Minerva Anestesiologica, vol. 79, no. 1, pp. 62-73, 2013.

[3] C. Loubert, "Fluid and vasopressor management for Cesarean delivery under spinal anesthesia: continuing professional development," Canadian Journal of Anesthesia, vol. 59, no. 6, pp. 604619, 2012.

[4] W. D. N. Kee, "Prevention of maternal hypotension after regional anaesthesia for caesarean section," Current Opinion in Anaesthesiology, vol. 23, no. 3, pp. 304-309, 2010.

[5] R. M. Lewinsky and S. Riskin-Mashiah, "Autonomic imbalance in preeclampsia: Evidence for increased sympathetic tone in response to the supine-pressor test," Obstetrics \& Gynecology, vol. 91, no. 6, pp. 935-939, 1998.

[6] J. R. Melchor, Á. Espinosa, E. M. Hurtado et al., "Colloids versus crystalloids in the prevention of hypotension induced by spinal anesthesia in elective cesarean section. A systematic review and meta-analysis," Minerva Anestesiologica, vol. 81, no. 9, pp. 10191030, 2015.

[7] A. Macarthur and E. T. Riley, "Obstetric anesthesia controversies: Vasopressor choice for postspinal hypotension during cesarean delivery," International Anesthesiology Clinics, vol. 45, no. 1, pp. 115-132, 2007. 
[8] P. Tamilselvan, R. Fernando, J. Bray, M. Sodhi, and M. Columb, "The effects of crystalloid and colloid preload on cardiac output in the parturient undergoing planned cesarean delivery under spinal anesthesia: a randomized trial," Anesthesia \& Analgesia, vol. 109, no. 6, pp. 1916-1921, 2009.

[9] S. Madijebara, A. Ghosn, G. Sleilaty et al., "Prevention of hypotension after spinal anesthesia for cesarean section 6\% hydroxyethyl starch 130/0.4 (Voluven ${ }^{\circledR}$ ) versus lactated Ringer’s solution," Journal Medical Libanais, vol. 56, no. 4, pp. 203-207, 2008.

[10] R. Varshney and G. Jain, "Comparison of colloid preload versus coload under low dose spinal anesthesia for cesarean delivery," Anesthesia: Essays and Researches, vol. 7, no. 3, p. 376, 2013.

[11] R. A. Dyer, Z. Farina, I. A. Joubert et al., "Crystalloid preload versus rapid crystalloid administration after induction of spinal anaesthesia (coload) for elective caesarean section," Anaesthesia and Intensive Care, vol. 32, no. 3, pp. 351-357, 2004.

[12] A. R. Rao and G. Vijaya, "Mahendra VVN: comparison of effects of preloading and coloading with ringer lactate," IOSR Journal of Dental and Medical Sciences, pp. 14-57, 2015.

[13] A. Banerjee, R. M. Stocche, P. Angle, and S. H. Halpern, "Preload or coload for spinal anesthesia for elective Cesarean delivery: A meta-analysis," Canadian Journal of Anesthesia, vol. 57, no. 1, pp. 24-31, 2010.

[14] Z. Farid, R. Mushtaq, S. Ashraf, and K. Zaeem, "Comparative efficacy of crystalloid preloading and co-loading to prevent spinal anesthesia induced hypotension in elective caesarean section," Pakistan Journal of Medical and Health Sciences, vol. 10, no. 1, pp. 42-45, 2016.

[15] P. Jain and D. Valecha, "Comparative Evaluation of Preloading and Coloading of Crystalloids to Prevent Spinal Induced Hypotension in Caesarean Section," International Journal of Contemporary Medical Research, pp. 411-414, 2017.

[16] M. Khan, A. Waqar-ul-Nisai Farooqi, and N. Ahmad, "Qaz S: Crystalloid Co-Load: A Better Option Than Crystalloid PreLoad For Prevention Of Postspinal Hypotension In Elective Caesarean Section," Internet J Anesthesiol, pp. 32-31, 2013.

[17] A.-Y. Oh, J.-W. Hwang, I.-A. Song et al., "Influence of the timing of administration of crystalloid on maternal hypotension during spinal anesthesia for cesarean delivery: Preload versus coload," BMC Anesthesiology, vol. 14, article no. 36, 2014.

[18] M. Sarkar, R. J. Chanda, D. Bhar, D. Roy, J. Mandal, and P. Biswas, "Comparis on of crystalloid preloading and crystalloid coloading in emergency caesarean section for fetal distress: a prospective study," Journal of Evolution of Medical and Dental Sciences, vol. 3, no. 7, pp. 1774-1781, 2014.

[19] S. Shah, A. Iqbal, and S. S. Naqvi, "SS: Comparison of crystalloid preloading and crystalloid co-loading for prevention of spinal anesthesia induced hypotension," in Pak Armed Forces Med, vol. 65, pp. s231-s235, 65, 2015.

[20] A. Sharma, P. K. Gupta, S. N. Singh, and D. Uprety, "Crystalloid prehydration versus cohydration for prevention of hypotension during spinal anaesthesia for elective caesarean section," Health Renaissance, vol. 12, no. 3, p. 190, 2016.

[21] A. Williams, L. Afzal, J. Jacob, and M. Verghese, "Crystalloid preload versus crystalloid coload for parturients undergoing cesarean section under spinal anesthesia," Journal of Obstetric Anaesthesia Critical Care, vol. 2, no. 1, pp. 10-15, 2012.

[22] J. Higgins and S. E. Green, "SE: Cochrane Handbook for Systematic Reviews of Interventions Version 5.1.0. The Cochrane Collaboration," Naunyn-Schmiedebergs Archiv für experimentelle Pathologie und Pharmakologie, vol. 2011, no. 14, p. S38, 2011.

[23] J. P. T. Higgins, S. G. Thompson, J. J. Deeks, and D. G. Altman, "Measuring inconsistency in meta-analyses," British Medical Journal, vol. 327, no. 7414, pp. 557-560, 2003.

[24] G.-Z. Ning, S.-L. Kan, L.-X. Chen, L. Shangguan, S.-Q. Feng, and Y. Zhou, "Rivaroxaban for thromboprophylaxis after total hip or knee arthroplasty: A meta-analysis with trial sequential analysis of randomized controlled trials," Scientific Reports, vol. 6, Article ID 23726, 2016.

[25] X. Wan, W. Wang, J. Liu, and T. Tong, "Estimating the sample mean and standard deviation from the sample size, median, range and/or interquartile range," BMC Medical Research Methodology, vol. 14, article 135, 2014.

[26] C. C. Rout, S. S. Akoojee, D. A. Rocke, and E. Gouws, "Rapid administration of crystalloid preload does not decrease the incidence of hypotension after spinal anaesthesia for elective Caesarean section," British Journal of Anaesthesia, vol. 68, no. 4, pp. 394-397, 1992.

[27] F. J. Mercier, "Fluid loading for cesarean delivery under spinal anesthesia: Have we studied all the options?" Anesthesia \& Analgesia, vol. 113, no. 4, pp. 677-680, 2011.

[28] J. T. Tamsma, H. J. Keizer, and A. E. Meinders, "Pathogenesis of malignant ascites: Starling's law of capillary hemodynamics revisited," Annals of Oncology, vol. 12, no. 10, pp. 1353-1357, 2001.

[29] S. Tølløfsrud, G. I. Elgjo, D. S. Prough, C. A. Williams, D. L. Traber, and G. C. Kramer, "The dynamics of vascular volume and fluid shifts of lactated Ringer's solution and hypertonic-salinedextran solutions infused in normovolemic sheep," Anesthesia \& Analgesia, vol. 93, no. 4, pp. 823-831, 2001.

[30] A. M. Pouta, J. Karinen, O. J. Vuolteenaho, and T. J. Laatikainen, "Effect of intravenous fluid preload on vasoactive peptide secretion during Caesarean section under spinal anaesthesia," Anaesthesia, vol. 51, no. 2, pp. 128-132, 1996.

[31] S. Suga, K. Nakao, H. Itoh et al., "Endothelial production of C-type natriuretic peptide and its marked augmentation by transforming growth factor-beta. Possible existence of 'vascular natriuretic peptide system,"' The Journal of Clinical Investigation, vol. 90, pp. 1145-1149, 1992.

[32] R. G. Hahn and C. Svensén, "Plasma dilution and the rate of infusion of Ringer's solution," British Journal of Anaesthesia, vol. 79, no. 1, pp. 64-67, 1997.

[33] A. S. Hollister and T. Inagami, "Atrial natriuretic factor and hypertension a review and metaanalysis," American Journal of Hypertension, vol. 4, no. 10, pp. 850-865, 1991.

[34] C.-A. Ewaldsson and R. G. Hahn, "Volume kinetics of Ringer's solution during induction of spinal and general anaesthesia," British Journal of Anaesthesia, vol. 87, no. 3, pp. 406-414, 2001. 


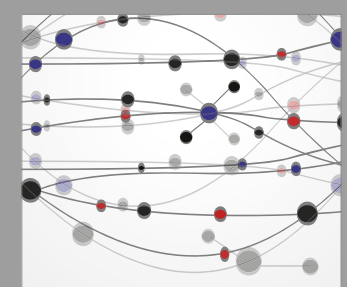

The Scientific World Journal
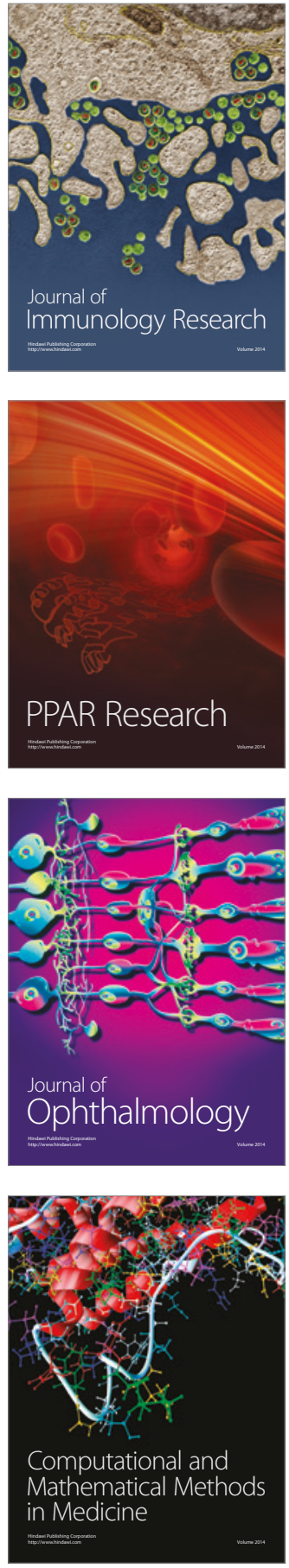

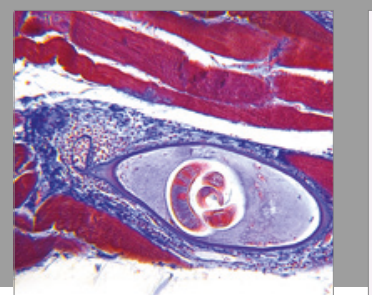

Gastroenterology Research and Practice
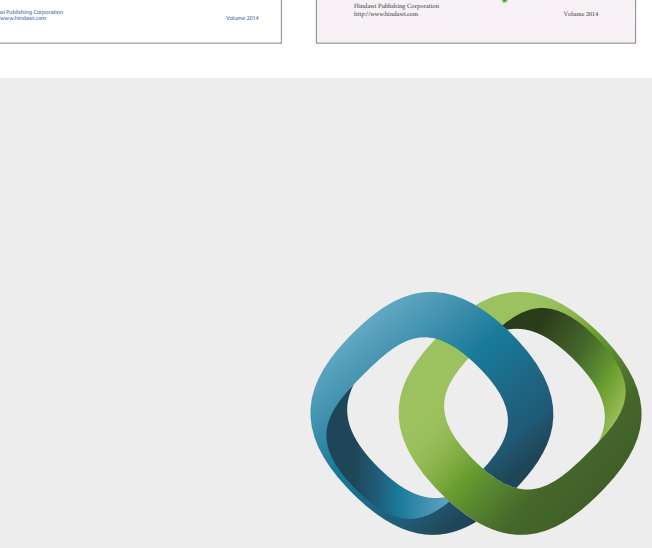

\section{Hindawi}

Submit your manuscripts at

https://www.hindawi.com
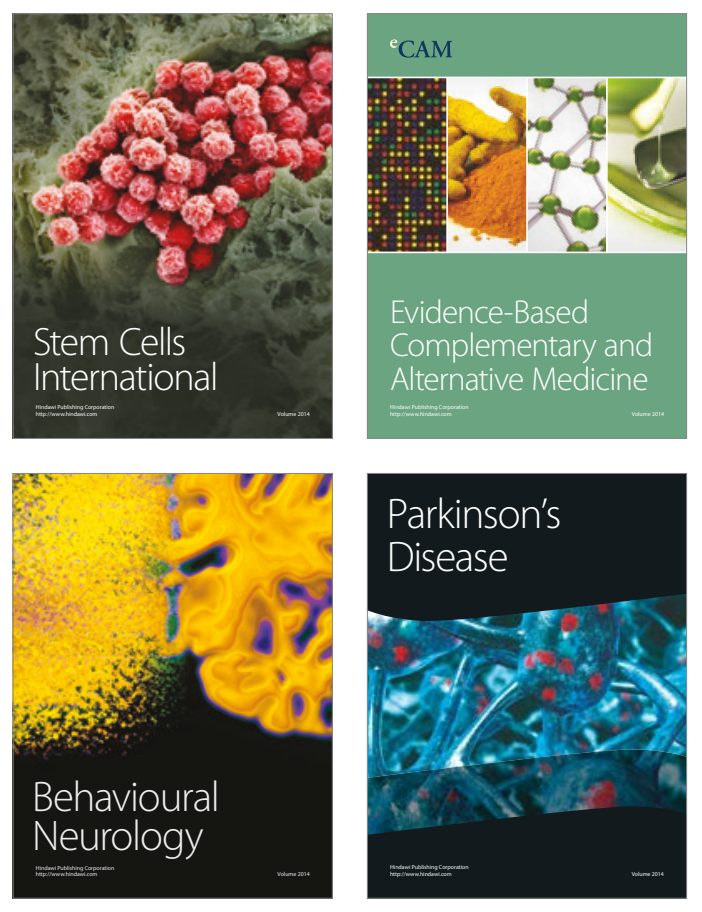
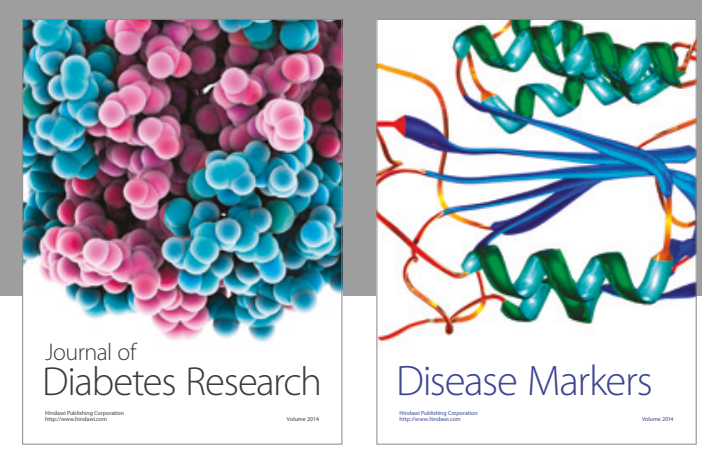

Disease Markers
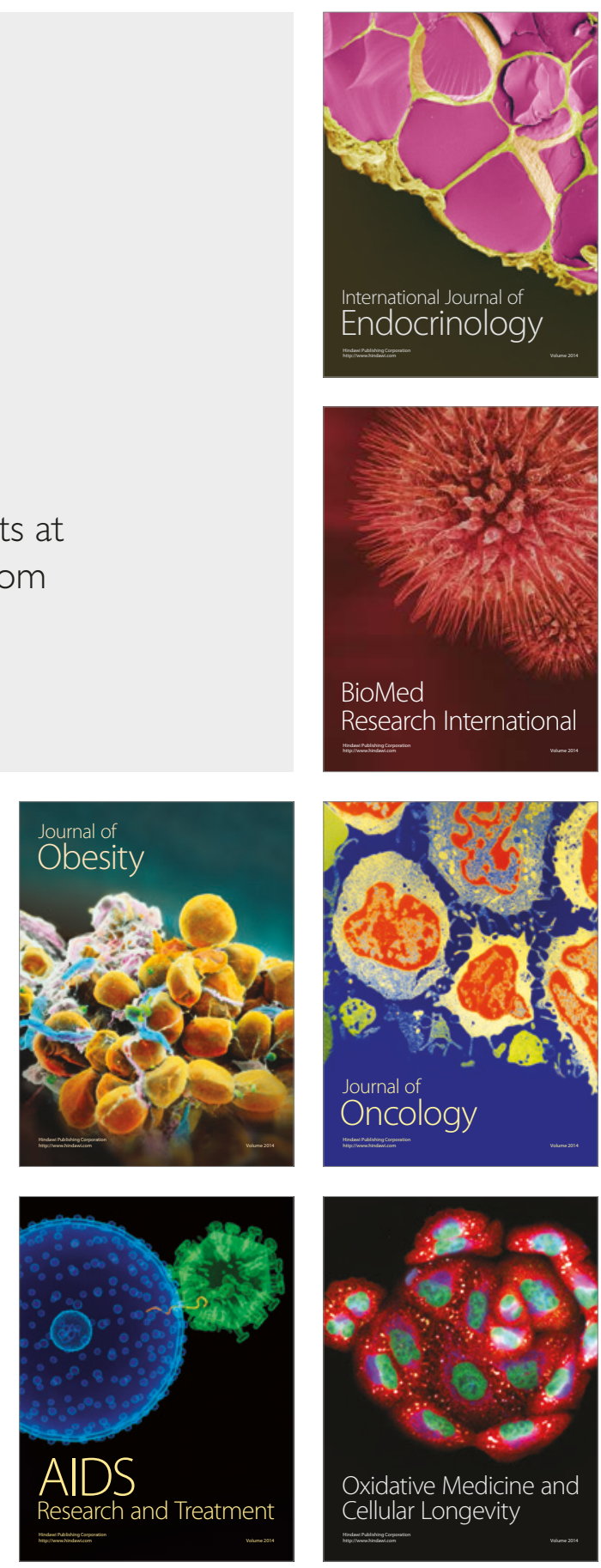